\title{
O poder das narrativas na legitimação e valoração da arte contemporânea ${ }^{1}$
}

\author{
BRUNA FETTER
}

\begin{abstract}
Bruna Fetter é pesquisadora e curadora independente. Doutora em História, Teoria e Crítica de Arte pelo Programa de Pós-Graduação em Artes Visuais da UFRGS, tem se dedicado a investigar questões que envolvem o sistema da arte e os processos de legitimação e constituição de valor na arte contemporânea. Foi contemplada com uma bolsa Fulbright para desenvolver parte de sua pesquisa de Doutorado na New York University. É membro da Associação Brasileira de Crítica de Arte (ABCA) e da Associação Nacional dos Pesquisadores de Artes Plásticas (ANPAP).
\end{abstract}

1 Este artigo advém da pesquisa de Doutorado intitulada "Narrativas conflitantes e convergentes: as feiras e os ecossistemas contemporâneos da arte", defendida no Programa de Pós-Graduação em Artes Visuais da UFRGS, em 2016 


\section{- RESUMO}

Este artigo propõe elencar algumas das principais narrativas na legitimação e valoração da arte contemporânea, analisando seus impactos no sistema da arte. Apesar de tais narrativas se manifestarem em diferentes instâncias do sistema - como instituições, colecionadores e mesmo nos artistas -, elas têm no mercado sua principal plataforma. Compreendendo que elas surgem e se solidificam em função de diversos interesses, vemos na opacidade e desregulamentação do próprio mercado de arte o motivo de sua crescente relevância. Assim, apontamos nesse estudo três das mais frequentes narrativas no funcionamento do sistema contemporâneo, sendo elas: 1) a arte como investimento; 2) o empresariamento do artista e 3) a arte global, que seria gerada na chamada era pós-passaporte, ou seja, em um mundo globalizado no qual a origem dos artistas seria cada vez menos relevante. O poder atribuído a essas narrativas está diretamente relacionado aos diferentes contextos institucionais e circuitos comerciais nos quais se inserem. No entanto, elas estão presentes em diferentes graus nas variadas latitudes do mundo da arte.

\section{PALAVRAS-CAVE}

Mercado da arte, sistema da arte, narrativas, legitimação, globalização.

\section{ABSTRACT}

As the title indicates, this article proposes to verify some of the main legitimation and valuation narratives of contemporary art, analyzing their impacts on the art system. Although such narratives appear in different instances of the system - as institutions, collectors and even artists - they have the market as their main platform. Understanding that they arise and solidify according various interests, we see in the opacity and deregulation of the art market a reason for their increasing relevance. Thus, we point out in this study three of the most frequent narratives in the functioning of the contemporary system, being: 1) art as an investment; 2) entrepreneurship of the artist and 3) global art, which is generated in the postpassport era, that is, in a globalized world in which the origin of the artists would be less and less relevant. The power attributed to these narratives is related to different institutional contexts and commercial circuits in which they are inserted. However, they are present, in different degrees, in every latitude of the art world.

\section{- KEYWORDS}

Art Market, art system, narratives, legitimization, globalization.

\section{Narrativas conflitantes e convergentes}

O mundo contemporâneo apresenta uma série de desafios para o funcionamento do sistema da arte. Mudanças econômicas, sociais, culturais e organizacionais produziram um mercado global de arte, cuja influência atinge desde a produção artística até a programação de importantes instituições. Começando por questões amplas de ordem financeira, e chegando a mudanças estruturais no sistema contemporâneo da arte e seus agentes de legitimação, cabe perguntar: quais os reflexos da crescente importância do mercado para os diferentes circuitos artísticos? 
Mesmo que os distintos dados e relatórios existentes a respeito do tamanho e crescimento do mercado da arte se utilizem de diferentes abordagens, metodologias e formas de mensuração, a natureza do mercado de arte não nos permite ter exatidão a respeito desses números. Mesmo se tomarmos os resultados oficiais atingidos nos leilões, ainda nos faltam informações e dados confiáveis para mensurar o tamanho do mercado como um todo, ou mesmo compreender os processos de formação de preços de obras de arte contemporânea fora do seu ambiente. 0 que temos, além dos registros de casas leiloeiras, são estimativas de movimentações financeiras a partir das vendas realizadas em feiras e galerias.

Entendemos aqui que mais importante do que nos fixarmos em números é compreender questões de ordem econômica que embasam esses direcionamentos, e algumas de suas consequências para o sistemas da arte. Os dados de que dispomos ainda são baseados em um tipo de mensuração que é falha em sua essência. No entanto, conhecê-los cumpre uma dupla função: 1) mostrar a relevância de compreender o que está acontecendo nos mercados de arte e seus reflexos para os circuitos artísticos; e 2) estabelecer um parâmetro mínimo do que as pessoas do meio utilizam e compartilham, enquanto informação para tomada de decisão sobre esses mesmos mercados. Assumindo a impossibilidade de uma mensuração dos mercados da arte que dê conta de suas amplitudes e reverberações, toda a qualquer tentativa de apreendê-lo parte de limitações intrínsecas à natureza desse objeto opaco e não regulamentado.

Este artigo parte da noção de que o mercado de arte é formado, mais do que por números que o quantificam, por narrativas que o definem, qualificam e ditam seu desenvolvimento. Às vezes convergentes, outras conflitantes, tais narrativas mostram os paradoxos que constituem a relação dos diferentes atores com o mercado e suas diversas instâncias.

Ao pesquisar o mercado de arte de forma sistemática, há uma palavra que aparece com certa frequência nos mais variados discursos - sejam eles advindos do ambiente acadêmicos, da imprensa, de atores atuantes no mercado em si ou mesmo de artistas - e com a qual temos rapidamente que aprender a lidar: a palavra paradoxo. Essa noção surge repetidas vezes ao abordarmos questões de autonomia, valor e mercadoria. Graw (2009) apresenta como esses paradoxos se estabelecem em diferentes níveis no sistema da arte, e como o mercado se estrutura ao redor deles. Para a autora, arte e mercado são mutuamente dependentes, um sendo necessário para configurar a existência do outro. Mesmo que essa dependência ocorra a partir de uma série de parâmetros específicos de legitimação do mundo da arte - reguladores dessa condição - e que obras de arte possuam uma lógica própria de funcionamento e circulação, essas questões são sempre permeadas ou restringidas pelo mercado.

No entanto, como aponta a autora alemã, se o mercado surge como algo tão fundamental para a existência da arte, por que ele é comumente visto como um empecilho para o seu desenvolvimento e autonomia? Por que ele é atacado nos discursos dos críticos e artistas, como sendo algo perigoso, potencialmente prejudicial para a produção, coibidor de experimentação? Graw (2009) indica outro paradoxo elementar da relação arte e mercado: a tendência de artistas, curadores e mesmo galeristas a banir o mercado, como se fosse um elemento externo, algo com o qual eles não se identificam. No entanto, ela afirma que isso se trata apenas 
de um recurso discursivo, que geralmente reforça as estratégias de marketing ao redor da carreira do artista. Ou seja, reclamar das sistemáticas do mercado, dos processos que configuram arte como mercadoria e colecionadores como investidores é necessário para fazer parte do sistema da arte com sucesso. Para a autora, a raiz desse paradoxo entre participação no mercado e rejeição a ele localiza-se na compreensão de arte como commodity. Como dito anteriormente, arte e mercado são indissociáveis. Logo, o aspecto mercadológico da obra de arte é parte constituinte da mesa enquanto obra: ela é arte, mas também é uma mercadoria. Um tipo diferenciado e único de mercadoria.

Essa aparente contradição tem reflexos em questões que envolvem a valoração das obras de arte. Isso porque a predominância de uma mentalidade capitalista de espetacularização e de consumo atinge a sociedade como um todo e gera reflexos no mundo artístico. Como apresentam Lipovetsky e Seroy (2011, p. 39): "O fato está aí: o espírito do tempo converteu-se no espírito do capitalismo, funcionando como uma cultura sem fronteiras, uma cultura-mundo". Tal hegemonia da lógica do mercado e da concorrência é também discutida por Zizek (2011), que afirma que vivemos numa época de naturalização da economia. Essa naturalização da economia nada mais é do que a aceitação de uma mercantilização generalizada, que percorre todas as áreas da vida social, chegando à cultura e fetichizando espaços antes refratários à sua ação, como é o caso da arte.

A partir desse cenário, Lipovetsky e Seroy (2015) defendem que as lógicas produtivas do sistema mudaram: esferas se hibridizaram e interpenetraram. Não estamos mais no tempo em que produção industrial e cultura remetiam a universos separados, radicalmente inconciliáveis; estamos no momento em que sistemas de produção, distribuição e consumo são impregnados e remodelados por operações de natureza fundamentalmente estética. De forma semelhante, os discursos que acompanham as lógicas produtivas também sofreram alterações.

Para Brandellero (2016), é majoritariamente através de recursos discursivos que o mercado de arte opera. Isso porque, para além da falta de dados completos ou mesmo confiáveis de mensuração do mercado, é nas lacunas de informação concretas que ele prospera. A autora aponta, então, três mecanismos que caracterizam os mercados da arte, diferenciando-os de outros tipos de mercados: 1) status como princípio organizador; 2) redes como base das relações sociais; e 3) narrativas como prática e rotina.

A primeira característica nos diz que o mercado da arte funciona, pela excepcionalidade das características do objeto artístico, enquanto commodity, com base nos diferentes níveis de informação e conhecimento a seu respeito. Ou seja, há uma hierarquia de status no acesso aos dados que conferem vantagens ou desvantagens a diferentes atores dos circuitos artísticos, dependendo de sua reputação e condição financeira. A autora ressalta, ainda, que, em mercados emergentes, a desigualdade na distribuição da informação é maior, pois as pessoas tendem a valorizar o que é mais "conhecido".

A segunda característica aponta as redes (networks) como o cerne das relações sociais nos mercados da arte. As redes constituem ambientes em que os atores e instituições podem ativar diferentes narrativas, desde que as lógicas por trás delas sejam compartilhadas entre tais atores. As redes sociais demarcam como os participantes dos mercados da arte disputam posições tanto nas esferas local 
quanto global (BRANDELLERO, 2016). Para além da compreensão de mercado como a instância em que se realizam trocas comerciais diretas - ou seja, compra e venda de obras de arte -, podemos entendê-lo como uma esfera que perpassa praticamente todas as relações estabelecidas no âmbito das relações sistêmicas da arte. Em menor ou maior escala, instâncias legitimadoras institucionais ou de caráter independente, críticas ou comerciais, colaboram na constituição de valor para diferentes artistas e obras. Assim, tais instâncias situam artistas em um mapa de valoração, de acordo com sua forma de atuação dentro das diferentes possibilidades do sistema e suas repercussões históricas, estéticas, culturais, sociais e comerciais.

A terceira característica - e a mais importante para a análise aqui apresentada - parte de como as narrativas de validação desenvolvidas a partir do mercado são fundamentais tanto na legitimação dos artistas quanto na precificação de suas obras. Como Velthuis (2005) aponta, os padrões objetivos e os custos de produção não são suficientes para determinar e quantificar seu valor simbólico. Como o valor de um trabalho de arte não é uma equação resultante apenas dos seus valores de uso e de troca, seu preço acaba por ser definido na própria interação do mercado. Assim, estar envolvido em processos de scripting, ou criação de narrativas, é uma parte importante de participar de mercados baseados em status, como é o caso do mercado da arte. Tais narrativas acabam substituindo o valor objetivo de um produto, típico em mercados que funcionam segundo as leis clássicas de oferta e procura no estabelecimento dos seus preços, permitindo, portanto, a reprodução das hierarquias e a manutenção do status de quem tem o poder de gerá-las.

Além de fornecer uma base para a "construção de sistemas de significado comum" (BERGER e LUCKMANN apud BRANDELLERO, 2016), scripts atuam como estruturas cognitivas e interpretativas que ajudam a dar sentido às ações de atores $e$ instituições de um campo, constituindo-se em lógicas de ação que embasam tomadas de decisão e atuações estratégicas nos mercados. Para além dos aspectos práticos que resultam em relações comerciais de compra e venda de produtos, as narrativas também lidam com questões de inserção geoeconômica. Assim, qualquer ator individual ou institucional que possua acesso a esferas globais (ou seja, um alto índice de globalização nos circuitos artísticos) acaba por projetar uma imagem positiva em mercados locais.

Dessa forma, podemos compreender que os mercados da arte não necessariamente são compostos pelos números e dados contidos nos relatórios anualmente divulgados, mas sim que eles são constituídos por um somatório de narrativas que os englobam. Ou seja, o entendimento que temos desses mercados tendem a ser um composto ficcional advindo das relações entre o que se vê e o que se diz, entre o que se faz e o que se pode fazer. “(...) O real é sempre o objeto de uma ficção, isto é, de uma construção do espaço onde se juntam o visível, o dizível e o realizável" (RANCIÈRE apud CANCLINI, 2012, p. 232). Assim, o mercado de arte não é apenas constituído pelas operações comerciais comprovadamente efetuadas, mas também se estabelece através das formas de visibilidade que conferem valor.

O real precisa ser ficcionalizado para ser pensado. Essa proposição deve ser distinguida de todo discurso - positivo ou negativo - segundo o qual tudo seria "narrativa", com alternâncias entre "grandes" e 
"pequenas" narrativas. A noção de "narrativa" nos aprisiona nas oposições do real e da farsa. Não se trata de dizer que tudo é ficção. Trata-se de constatar que a ficção da era estética definiu modelos de conexão entre apresentação dos fatos e formas de inteligibilidade que tornam indefinida a fronteira entre razão dos fatos e razão da ficção, e que esses modos de conexão foram retomados pelos historiadores e analistas da realidade social (RANCIÈRE, 2005, p. 58).

Tais crenças fazem parte da vida das pessoas que estão envolvidas nos circuitos artísticos. Essas pessoas por sua vez, fazem parte do fenômeno da constituição discursiva dos mercados. Elas estão contaminadas por esses discursos e, mesmo negando-os, os replicam diariamente. No mundo da arte, talvez mais do que em qualquer outro lugar, um fato diz muito pouco sobre o seu significado efetivo. No entanto, os significados podem ser gestados e são decisivos nos debates sobre a interpretação do jogo, sua legitimidade, mediação e as apropriações que dele são feitas.

A partir da pesquisa realizada ${ }^{2}$, uma série de narrativas foram se evidenciando. Muitas vezes, tais narrativas estão tão entrelaçadas que poderiam ser descritas num continuum, sem nenhum tipo de divisão entre elas. Para fins de apresentação e análise, elas foram agrupadas em blocos. É importante ressaltar que praticamente todos os pontos apresentados em cada bloco poderia estar localizado em outro, às vezes em vários, tamanha a dificuldade de estabelecer delimitações. Dessa forma, 1) a arte como investimento; 2) o empresariamento do artista; e 3) a arte global na era pós-passaporte são algumas das narrativas verificadas com maior frequência na atualidade.

\section{Arte como investimento}

Ao longo das últimas décadas, foi possível detectar um significativo crescimento da participação do papel do mercado em relação aos circuitos artísticos, em especial àqueles vinculados à arte contemporânea. A China e os Estados Unidos vêm se revezando nos últimos anos na posição de líder do mercado global. De acordo com a edição de 2013 do Relatório da ArtPrice $^{3}$, as receitas da China subiram $21 \%$ em 2012, obtendo um total de US $\$ 4,1$ bilhões, enquanto os EUA registraram um crescimento de cerca de $20 \%$, com mais de US\$ 4 bilhões em vendas. Somados, ambos os países controlam cerca de $70 \%$ do mercado de arte em termos de volume de vendas. A distância entre o faturamento desses dois países e dos demais tem aumentado. Somando US\$ 2,1 bilhões, o Reino Unido gerou metade das receitas dos líderes. A França, quarta no ranking, fez US\$ 549 milhões (4,5\% do mercado), seguida da Alemanha (US\$ 207 milhões, 1,7\% do mercado), Suíça

\footnotetext{
2 O trabalho de campo relativo à tese de doutorado - da qual este artigo é uma parte - englobou visitas a cerca de 25 feiras de arte no Brasil, EUA, Argentina e Peru. Além disso, ter contado com bolsa Bolsa CAPES/Fulbright para a realização do doutorado sanduíche na New York University (Nova lorque, Estados Unidos) foi fundamental para o desenvolvimento da pesquisa.

3 A ArtPrice é uma plataforma on-line (www.artprice.com) que agrega informações a respeito do mercado de arte global. Possuindo uma grande base de dados sobre a evolução do mercado arte, valores de obras, biografias de artistas, índices de confiança do mercado, leilões, recordes etc., também funciona como uma ferramenta de intermediação para compra e venda de obras. Disponibiliza anualmente um Relatório, onde analisa os movimentos do mercado no ano anterior e aponta as principais tendências do setor.
} 
(US\$ 159 milhões, 1,3\% do mercado) e Itália (US\$ 110 milhões, 0,9\% do mercado).

Em termos de Brasil, até o início dos anos 2010, era quase absoluto o desconhecimento sobre o tamanho desse mercado. Estimava-se, por exemplo, que o mercado brasileiro correspondesse a um percentual que girasse em torno de 0,25 a 0,50\% (KORNIS; EARP, 2012) de participação no mercado mundial, mas faltavam dados concretos para serem utilizados como referência. Se nos voltarmos aos mapeamentos realizados pelo Projeto Latitude ${ }^{4}$, em 2011 e 2012, foram registrados crescimentos anuais de 22,5\% e, em 2013, de 27,5\%.

Apesar da opacidade e da falta de regulamentação desse meio, que dificultam o acesso à informação sobre o mercado e geram limitações na mensuração do seu crescimento, ele é incontestável. Portanto, não é sobre uma narrativa de crescimento que nos interessa aprofundar, mas refletir sobre o fato de que, a partir desse crescimento, a arte passou a adquirir também uma faceta de investimento. Se até os anos 2000 ainda prevalecia a ideia de "amor à arte" como motivo de aquisição de uma obra, agora ela até pode partir desse tipo de afirmação, mas não se esgota nela.

Há aqui uma questão comportamental característica do meio da arte que está passando por profundas transformações: os protocolos sociais envolvidos ao se falar sobre dinheiro. Ao analisar o encontro entre arte e dinheiro, Bourdieu (2002, p. 19) afirmou ser o "comércio das coisas de que não se faz comércio", sendo o mercado comumente visto como um tipo de degeneração prática dos objetivos da arte, um desvio de seus objetivos mais elevados. Esta regra comportamental, que ditava que não se devia falar abertamente a respeito de cotações de obras e valorização do trabalho dos artistas, ainda persiste em alguma medida. Sobre isso, Moulin (2007) afirma que a dificuldade de análise dos mercados de arte não revela apenas a negação da economia nos mundos da arte, mas também a assimetria de informação que caracteriza esse mercado.

No entanto, o mercado de arte se transformou em um grande negócio, o qual movimenta bilhões de dólares anualmente em todo o mundo, e passou a gerar interesse para diferentes grupos sociais. Acompanhando essas transformações no sistema da arte, os protocolos sociais também têm mudado. Apesar do protocolo de negar a atuação do mercado ainda ser um mecanismo vigente, ele em funcionado de forma paradoxal: a crítica ao mercado reafirma sua existência e função, creditando ao seu funcionamento papel fundamental nos processos de formação de valor da arte, em especial, da arte contemporânea. Nas últimas décadas, a arte deixou de ser considerada patrimônio para ser vista como uma classe de investimento. Com isso, o mercado passou a demandar novos serviços e um afluxo de profissionais com outro tipo de qualificação.

Dentro dessa narrativa de arte como investimento, algumas figuras ocupam destaque especial: os colecionadores, os investidores e os flippers. O colecionador sempre teve um papel de destaque na viabilização de obras de arte, atuando há séculos como mecenas e dando suporte material à produção artística. A principal

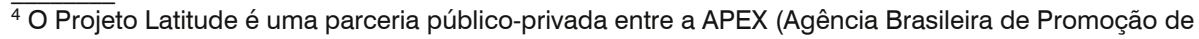
Exportações e Investimentos) e a ABACT (Associação Brasileira de Arte Contemporânea). Foi criado em 2007, com o objetivo de promover a internacionalização do mercado brasileiro de arte contemporânea. Tem dentre suas ações a realização de Relatórios Setoriais, objetivando aumentar o conhecimento a respeito do mercado de arte brasileiro. 
diferença de atuação talvez resida, hoje, na forma autônoma e no protagonismo que as operações conduzidas por grandes colecionadores estão obtendo. Os investidores financeiros surgiram como consequência da significativa elevação de preços e de artistas contemporâneos nos últimos anos.

Um ator que tem ocupado crescente espaço na mídia e que, assim, tem reforçado a narrativa da arte como investimento são os especuladores, também chamados de flippers. Atuando no mundo da arte de forma semelhante a como atuam no mercado financeiro, os flippers não são bem-vistos pelos atores estabelecidos, que os veem como uma ameaça ao funcionamento dos mercados de arte, uma vez que compram e vendem trabalhos como se fossem ações da bolsa de valores, inclusive "torrando" alguns artistas sem que eles tenham a oportunidade de solidificar suas carreiras. Eles não estão interessados no valor simbólico, mas naquilo que podemos chamar de valor viral: o valor popularidade, reconhecimento imediato e alta visibilidade (VELTHUIS, 2014).

Para além da ascensão desses atores no sistema contemporâneo da arte, a narrativa da arte como investimento também tem outros desdobramentos, que vão de alterações nos mencionados mecanismos de disputa por poder e validação, a reflexos na própria produção artística. Em um ambiente em que qualidade artística muitas vezes pode ser confundida com o valor atingido no mercado, surgem as perguntas: como fica o papel e aposição do artista nesse cenário? O que se passou a esperar dele (tanto em termos de postura profissional como de produção)?

\section{Empresariamento do artista}

O valor de mercado de determinada obra é definido a partir de uma equação complexa, baseada na constituição de seu valor simbólico. Para Graw (2009), haveria uma mais-valia intelectual que representaria uma espécie de ganho epistemológico, somente possível através da arte e da experiência estética. Isso diferenciaria objetos de arte de outras commodities, uma vez que tal ganho não permite a conversão automática da arte a categorias econômicas, e sua consequente redução a meros preços.

No entanto, obras de arte têm preços. Aqui observamos mais um paradoxo envolvendo as relações expostas, pois o preço de uma obra de arte está justamente baseado na compreensão de que ela possui um valor simbólico que não é quantificável. Ou seja, ela tem um valor de mercado e, ao mesmo tempo, é priceless. O valor simbólico "impagável” justificaria os preços elevados praticados no mercado.

$\mathrm{O}$ aspecto mercadológico da obra de arte tem sido constantemente reforçado nas últimas duas décadas. Um exemplo interessante nesse sentido é apontar que sua valoração e ciclos de vida têm seguido o funcionamento da indústria da moda, no qual as marcas possuem um papel fundamental (GRAW, 2009). Associando valor de mercado a um valor de experiência, para gerar um valor simbólico, a indústria da moda se baseia em bens de luxo, diretamente associados ao status do comprador. $\mathrm{Na}$ arte, os nomes de alguns artistas que ocupam o topo do ranking dos mais caros do mundo estão assumindo esse papel e convertendo-se em marcas.

Heinich (2005), ao avaliar as reconfigurações do estatuto de artista na época moderna e contemporânea, afirmou que "o artista, cada vez mais, não será mais só aquele que produz obras de arte, mas, sobretudo, aquele que consegue fazer-se 
reconhecer como artista" (p. 139). Com isso, a autora afirma que a construção de princípios de legitimação artística, para além da produção artística em si, tem dominado o sistema da arte.

Para embasar sua constatação, a autora explicita diferentes regimes profissionais que operaram e determinaram o sistema ao longo dos últimos séculos. Partindo de um regime artesanal do artista medieval, sucedido por um regime profissional do artista acadêmico e seguido pelo regime vocacional do artista romântico. Com a modernidade, teria havido transformações não apenas das representações acerca do que é ser um artista, como também da valorização do artista perante a sociedade, passando a constituir um novo regime, chamado por ela de regime de singularidade. Tal singularidade estaria baseada em dois pilares centrais: o da personalização, segundo o qual ninguém deve se assemelhar a outro; e o da excentricidade, que dita a constante busca por caminhos sempre inéditos, paradoxais ou mesmo bizarros.

Atualmente há um grau suplementar nesta reconfiguração da identidade de artista, pois existem múltiplas possibilidades dos modos de ser artista. A própria noção de carreira artística evoluiu paralelamente à evolução da identidade de artista e do lugar do mercado nos critérios do sucesso. Para tanto, o uso de recursos de publicidade e marketing tem se mostrado muito comuns. Aqui retomamos as ideias de Graw (2009), a associação do atual sistema da arte com a indústria da moda e as construções de valor, ao redor do nome de determinado artista e sua produção, funcionando como marcas.

Thompson (2012) ressalta que a marca é o resultado final das experiências que uma empresa desenvolve com seus clientes e com a mídia, durante um longo período, somado a um trabalho de marketing e relações públicas que ajuda a desenvolver e consolidar essas experiências. Quando se consegue transformar um produto em marca, ele adquire um valor monetário adicional, a chamada brand equity, que é a diferença de preço que as pessoas se dispõem a pagar pela marca em comparação com um produto genérico similar. De forma análoga, o valor de marca (ou da assinatura) tem exercido uma influência crescente na formação dos preços no mercado de arte.

E é em função do valor que essa assinatura adquire no meio artístico que os artistas passam a ser incorporados com status de celebridade (GRAW, 2009). "A era do capitalismo artista tardio é a era da dessacralização da criação, que corre paralela à estrelização dos criadores" (LIPOVETSKY; SEROY, 2015, p. 115). Velthuis (2005) chama esse culto à celebridade de superstar narrative.

Isso ocorre especialmente dentro de um contexto de intensa financeirização, no qual os compradores passaram a tratar a arte de uma forma especulativa, com particularidades e riscos próprios. E é na tentativa de buscar minimizar alguns dos riscos envolvidos que a procura por artistas reconhecidos ou com potencial de ascensão no mercado configura a instauração de um novo regime de carreira artística: de singularidade vigente durante o modernismo, a um regime de marca na contemporaneidade. Tal percepção se reflete nas palavras de Thompson, ao afirmar que "no mundo da arte contemporânea a gestão de marca pode substituir o juízo crítico" (THOMPSON, 2012, p. 8). Ou seja, numa época em que a compreensão do que é ou não arte não é unânime e passa por uma série de instâncias, uma marca forte pode ser o principal fator de investimento em uma obra. Por certo, há a narrativa da profissionalização do campo como um todo. No entanto, o que nos interessa é 
precisamente a narrativa que envolve não apenas os processos de profissionalização do artista, mas sim de seu empresariamento. Se pensarmos que preceitos como alto desempenho, eficiência e maximização de lucros já regem esse universo e influenciam, inclusive, o poder de livre escolha de seus envolvidos, devemos refletir sobre como consequências resultantes dessa crença no empresariamento podem estabelecer novos padrões de comportamento na classe artística e na produção contemporânea mais recente.

Em poucas décadas, a arte deixou de ser considerada apenas uma questão de amor desinteressado e passou a ser assunto de profissionais, inclusive dos profissionais do mundo financeiro. Junto com esses novos profissionais, o meio artístico viu uma lógica e um linguajar empresariais passarem a fazer parte da realidade cotidiana das situações de trabalho. Disso não escaparam nem os artistas, de quem se cobra posturas e aptidões que passavam longe daquilo que o senso comum costuma pensar a seu respeito.

Para além do perfil profissional expandido, cada ator viu o rol de exigências aumentar, sendo comum se ouvir o termo "empresa de um homem só" referindo a artistas. Ou seja, espera-se que, conjuntamente com sua produção artística, ele saiba escrever projetos, faça assessoria de impresa, crie e gerencie seu próprio site. Não é incomum ouvir o adjetivo empreendedor para descrever o perfil de artistas hoje. No entanto, esse multitarefas (multitasking) exigido pela contemporaneidade esconde contradições intrínsecas ao desempenho simultâneo de funções tão distintas. Como comenta o artista Fernandes-Halloran (2014), em artigo publicado no Hyperallergic:

É inegável que eu me beneficiei de ser empreendedor, fazendo um bom site, interagindo com pessoas que desempenham distintos papéis no mundo da arte, e buscando ativamente relacionamentos potencialmente produtivos. Mas, como uma regra tácita, eu deveria evitar algo no núcleo de ser um empreendedor: direcionar a produção pela demanda percebida, também conhecido como produzir o tipo de trabalho que vai vender. Ao fazê-lo, eu iria validar expectativas e normas, demonstrando que o que o mercado quer é o que eu quero fazer. Mas eu preciso vender o meu trabalho. Os sinais estão por toda parte como qual tipo de trabalho vende: obras que ficam bem na sala de uma pessoa rica, que combinam com opulência, e podem ser armazenadas e montadas de forma relativamente fácil. Quando a estação de feiras de arte vem, ela sempre traz um momento difícil, quando percebo a realidade do estado do mercado de arte e quão pouco ele tem a ver com o tipo de aspirações realizadas por mim e meus amigos artistas. E a nefasta pergunta inevitavelmente vem à minha cabeça: "O que eu posso fazer com o meu trabalho para ele se encaixar aqui?" (FERNANDES-HALLORAN, 2014) (tradução nossa) $^{5}$.

\footnotetext{
5 No original: It is undeniable that I have benefited from being entrepreneurial by making a nice website, interfacing with people playing various roles in the art world, and actively pursuing potentially productive relationships. But as an unspoken rule, I am supposed to avoid something at the core of being an entrepreneur: informing production by perceived demand, aka making work that will sell for the sake of selling. In doing so, I would validate expectations and norms, demonstrating that what the market wants is what I want to make. But I need to sell my work. The signs are everywhere as to what kind of work sells: stuff that looks good in a rich person's pad, that combines well with opulence, and can be stored and assembled relatively easily. When art-fair season comes around, it always brings a WTF moment when I realize the actual state of the art market and how little it has to do with the kind of aspirations held by myself and my friends who are artists. And that nefarious question inevitably pops into my head: "What can I do to my work that would make it fit in here?" (FERNANDES-HALLORAN, 2014).
} 
Sobre esse segundo ponto, os argumentos que reforçam a narrativa da arte como investimento tendem a ressaltar o aspecto comercial de determinado tipo de produção. Por arte comercial, compreendemos aquela produção artística orientada para tendências de mercado que facilitem a venda. Ou, ao menos, não apresentem questões que possam vir a prejudicá-la, como lidar com temáticas sociais complexas ou críticas político-econômicas. Por isso, as questões propostas por Tejo (2013) são extremamente relevantes para pensarmos como se dará essa convivência e negociação entre validação simbólica e reconhecimento mercadológico no futuro.

Talvez daqui para frente sejam poucos os que conseguirão responder de maneira firme às seduções do mercado e do deslumbre do reconhecimento rápido. Neste sentido, é importante então pontuarmos: o que é ser bem-sucedido hoje em dia? A geração que nasceu nos anos 1960 encontrou um quadro institucional e de mercado muito diferente da geração que nasceu nos anos 1980. Da mesma forma, não podemos desconsiderar o contexto político, econômico e tecnológico que abarca cada uma dessas gerações e que oferece expectativas, oportunidades e revezes, mas que principalmente trazem noções diferentes de tempo. Será que ser bem-sucedido seria ser abarcado concomitantemente pelo mercado e pela crítica? Ou seria criar sua própria forma de circulação e de inserção? (TEJO, 2013, p. 380).

Refletindo a respeito dessas questões, e do atual poder do mercado na legitimação da produção artística contemporânea, é com a falta de investimento público e com a ausência de uma estrutura interna que possa sustentar esse circuito para além do mercado que devemos nos preocupar. Ou seja, apesar de toda a força que creditamos ao mercado na atualidade, o valor atribuído a qualquer produção artística ainda passa pela validação simbólica do meio. O mercado e seus agentes estão cientes de que dependem das instâncias de validação simbólica para atingir valoração financeira. E que extrapolar o seu poder relativo de ditar os andamentos do sistema pode ser exatamente aquilo que the tira a legitimidade de seguir atuando a partir de posição tão privilegiada na atualidade.

\section{Arte global na era pós-passaporte}

A terceira narrativa é aquela que parte de uma aceitação de uma globalização efetiva, resultando em uma produção artística global (BELTING ET AL., 2013). Tal narrativa está baseada em dois pilares centrais. Um deles assume que o sistema contemporâneo da arte está configurado em um sistema global de circulação, que usa sua estrutura de rede para permitir fluxos de comunicação e trocas. O outro abraça essa estruturação para justificar uma linguagem global da arte contemporânea.

Refletindo a respeito, podemos apontar uma esfera social chamada de mundo da arte, com a sua estrutura geográfica facilmente compreensível e um número limitado de membros que operavam pequenas empresas independentes, transformada em uma indústria global corporativa governada pelo princípio da celebridade (GRAW, 2014). 
Canclini (2012) afirma que os novos hábitos dos usuários da rede e as misturas de formatos e alianças entre produtores de conteúdos visuais, textuais e software (vide a atuação dos flippers) estão incidindo nos espaços da arte, desde os museus até as bienais e as feiras. Nesse processo, foram alterados os vínculos entre criação, espetáculo, entretenimento e participação; as distinções entre o local e o global; autoria, reprodução e acesso; entre elaboração simbólica e interesse comercial. Não iremos aqui nos aprofundar nas formas de legitimação e circulação da produção artística, mas sim focar nos principais pontos que nutrem as estratégias discursivas que compõem a narrativa de uma arte global.

Esse tipo de narrativa reforça a noção de estarmos vivendo em um momento histórico no qual a origem não importaria mais. Dessa forma, a chamada era póspassaporte é componente essencial da narrativa de uma arte global. Nesse cenário, as categorias identitárias de reforço de origem, tal como arte brasileira, arte latinoamericana ou arte oriental, amplamente praticadas pelo mercado, são relativizadas.

Artistas de destaque no cenário internacional passam a circular na esfera global e a integrar a categoria de arte contemporânea. O paradoxo dessa categorização é que, apesar de ela a princípio parecer mais ampla e inclusiva por não ser delimitada por critérios meramente geográficos, na realidade corresponde a uma restrição ainda maior, a econômica. Este argumento se reforça no fato de que participam dessa categoria os artistas que atingem os maiores valores em leilões, além de comumente serem representados pelas mais prestigiadas galerias.

Tal afirmação indica uma série de questões que são parte constituinte dos meandros da narrativa da arte global, dentre elas a de que a maior inserção de artistas não ocidentais faria parte de uma tentativa de rever dívidas históricas de reconhecimento por parte dos países do centro, conferindo visibilidade à produção artística de regiões periféricas (BELTING, 2013). No entanto, muitos acreditam que tal estratégia não passa de uma forma neocolonialista de reescrever a história. Em especial porque a história da arte segue sendo escrita a partir do centro e dos critérios por ele estabelecidos.

Do ponto de vista das instituições, essa inclusão tem acontecido como um tipo de política de cotas viabilizada pelos grandes colecionadores das regiões periféricas, como Patricia Phelps de Cisneros e Estrelita Brodsky (ambas venezuelanas atuando em instituições nova iorquinas). Tais colecionadores, além de doarem obras para as coleções de grandes museus internacionais, também têm patrocinado cargos de curadores nessas mesmas instituições e contribuído para um maior conhecimento a respeito da produção artística dessas regiões dentro dos quadros dos museus, resultando em uma maior visibilidade dos mesmos. Ao inserir determinados artistas em circuitos de legitimação mais abrangentes, esses colecionadores acabam legitimando (logo, elevando os valores) de obras em suas próprias coleções (VELTHUIS, 2005).

No caso do mercado, a inclusão se dá por consequência da, acima mencionada, validação institucional, mas somente avança por questões de ordem prioritariamente econômicas. Ou seja, os artistas que acessam a categoria "arte contemporânea" somente permanecem aí se mantiverem ou elevarem seus preços de forma consistente, configurando-se como um bom investimento. E aí retornamos à primeira das narrativas apresentadas. 
Apesar de estarmos analisando aqui apenas as narrativas que circulam no meio social, a respeito das configurações sistêmicas e comerciais que englobam ou tangenciam a produção artística contemporânea, não podemos deixar de mencionar que essa linguagem global da arte contemporânea é tanto discursiva quanto estética. Nessa tarefa, trazemos aqui Hélio Oiticica, que, no início dos anos 1970, já tinha claro o quão redutor é tentar traçar uma raciocínio linear para tratar de questão tão complexa. Ele afirmou:

Sou contra qualquer insinuação de um "processo linear"; a meu ver, os processos são globais - uma coisa é certa: há um "abaixamento" no nível crítico, que indica essa indeciso-estagnação - as potencialidades criativas são enormes, mas os esforços parecem mingalar, justamente quando são propostas posições radicais; posições radicais não significam posições estéticas, mas posições globais vida-mundo - linguagem - comportamento (OITICICA, 1973, p. 148).

Essa linguagem global da arte contemporânea não está presente apenas nos trabalhos, mas nos termos usados por curadores e críticos para abordar esses trabalhos. É um vocabulário próprio que é fruto de tendências expressas nos discursos dos grandes curadores que está naturalizado nas universidades, textos de exposições, críticas e que reflete na (e é reflexo da) produção dos artistas. Ela permeia e define o que será discutido sobre arte e como isso será escrito, mas - antes disso - compõe o regime estético específico ao qual as obras são submetidas, a poética dos artistas (RANCIÈRE, 2005).

\section{Onde os paradoxos se encontram}

Este artigo apresentou narrativas que consolidam alguns dos rumos percorridos pelos mercados de arte nas últimas décadas. Elas certamente não são as únicas. No entanto, são recorrentes o suficiente para - em conjunto - resultarem em estruturas ficcionais inteligíveis e minimamente coordenadas, que ora originam novas narrativas ora alimentam e reforçam as já existentes. Para finalizá-lo, vamos retomar brevemente alguns dos pontos expostos. Talvez uma das questões mais significativas nesse contexto é que a grande maioria dos textos noticiando o mercado de arte:

(...) descreve processos no indicativo que são, ao mesmo tempo pejorativos, sem levar em conta que uma posição pessoal no campo da arte e a perspectiva que ela impõe sujeitam essa mesma percepção a um "refração" sistemática. E essa perspectiva só pode funcionar com base em uma lógica que designa o campo da arte como uma esfera em que os conflitos sobre direito normativo de interpretação como a participação decisiva no jogo não só obscurecem o próprio jogo, mas com ele o jogo todo (SCHULTHEIS, 2015, p. 13) (tradução nossa) ${ }^{6}$.

\footnotetext{
$\overline{6}$ No original: It describes processes in the indicative which are at the same time in pejorative, without taking into account that a personal position in the fields of art and the perspective it imposes subject this perception to a systematic "refraction". And this perspective itself can only function on the basis of a logic which designates the field of art as a sphere in which the conflicts over normative right of interpretation as the decisive stake in the game not only obscure the stake itself but with it the entire game (SCHULTHEIS, 2015, p. 13).
} 
O que a citação nos mostra é que os protocolos sociais mudaram desde as análises de Bourdieu (2002): de uma corrente negação do papel do mercado, passamos à sua aceitação, desde que atrelada a uma crítica a respeito desse mesmo papel. Chamando a isso de semântica performativa (performative semantics), Schultheis afirma que tal recurso retórico é especialmente aplicado em questões relativas ao mercado da arte.

Entender como se dão essas negociações de enunciação é uma forma de enxergar como os processos de validação se instauram, para além do que é estritamente dito. Tais movimentos podem nos ajudar a interpretar/decifrar algumas das tendências, em termos de atualização dos protocolos de ação para o mundo contemporâneo.

Dessa forma, faz sentido questionar os relatórios produzidos no âmbito do mercado e seus dados. Isso não significa deixar de utilizá-los ou desconsiderar sua relevância. Significa entender seu lugar de fala, seu viés específico, no momento de usar essas informações, o que não deixa de ser também uma forma de reproduzir a mesma semântica performativa acima mencionada. O importante é observarmos essas construções de maneira crítica, buscando compreender seus efeitos sobre o sistema da arte.

\section{Referências}

ART PRICE e AMMA. The Art Market in 2015. Disponível em: <http://imgpublic.artprice.com/pdf/rama2016_en.pdf >. Acesso em 7 de setembro de 2016.

BELTING, H.; BUDDENSIEG, A.; WEIBEL, P. (eds.). The global contemporary and the rise of new art worlds. Cambridge: MIT Press, 2013.

BENJAMIN, W. A obra de arte na época de sua reprodutibilidade técnica. Porto Alegre: Zouk, 2012.

BOURDIEU, P. A produção da crença: contribuição para uma economia dos bens simbólicos. São Paulo: Zouk, 2002.

BRANDELLERO, A. The Emergence of a Market for Art in Brazil In: Cosmopolitan Canvases: The Globalization of Markets for Contemporary Art. In: VELTHUIS, O.; CURIONI, S. B. (orgs.). Oxford University Press: 2015. p. 215-237.

<https://doi.org/10.1093/acprof:oso/9780198717744.003.0010>

CANCLINI, N. G. A sociedade sem relato: Antropologia e Estética da Iminência. São Paulo: Editora da Universidade de São Paulo, 2012.

FERNANDES-HALLORAN, B. Thinking About Art Practice and the Role of Compromise. In: Hyperallergic, 19/03/2014. Disponível em <http://hyperallergic.com/115200/thinking-about-art-practice-and-the-role-ofcompromise/ > . Acesso 14 de outubro de 2015. 
FETTER, B. W. Narrativas Conflitantes e Convergentes: as feiras e os ecossistemas contemporâneos da arte. 2016. 378 p. Tese de Doutorado - Programa de Pós-Graduação em Artes Visuais da UFRGS, Porto Alegre, 2016.

FIALHO, Ana Leticia. Pesquisa Setorial Latitude. O mercado de arte contemporânea no Brasil (4⿳⺈冂a edição). São Paulo: Latitude, 2015.2 Disponível em: <http://media.latitudebrasil.org/uploads/arquivos/arquivo/4-pesquisa-seto_2.pdf>. Acesso: 16 de novembro de 2015.

GRAW, I. High Price: Art Between the Market and Celebrity Culture. Sternberg Press, 2009. , I. The Gallerist's Hat. In: Texte Zur Kunst. 24 de dezembro de 2014. Jahrgang, Heft 96, p. 8297.

HEINICH, N. As reconfigurações do estatuto do artista na época moderna. In: Porto Arte. Porto Alegre: n²2, Instituto de Artes/UFRGS, 2005. p.137-147

KORNIS, G.; SÁ EARP, F. O Mercado de Artes Visuais: Características e Tendencias in Políticas Culturais: pesquisa e formação. São Paulo: Itaú Cultural; Rio de Janeiro: Fundação Casa de Rui Barbosa, 2012.

LIPOVETSKY, Gilles; SEROY, Jean. A cultura-mundo: resposta a uma sociedade desorientada. São Paulo: Companhia das Letras, 2011.

, G; SEROY, J.. A estetização do mundo: Viver na era do capitalismo artista. São Pualo: Companhia das Letras, 2015.

MOULIN, R. O Mercado da Arte: Mundialização e novas tecnologias. Porto Alegre: Zouk, 2007.

OITICICA, H. Brasil diarreia. In: GULLAR, F. (Org.). Arte Brasileira Hoje. Rio de Janeiro : Paz e Terra, 1973.

RANCIÈRE, J. A partilha do sensível: estética e política. São Paulo: EXO experimental org, 2005.

SCHULTHEIS, F. et al. When Art meets Money: Encounters at the Art Basel. Verlag der Buchhandlung Walher König, Köln. Trad: James Fearns, 2015.

TEJO, C. Conversa entre os curadores. In: DUARTE, L.; PEDROSA, A. ABC-Arte Brasileira Contemporânea. São Paulo: Cosac Naify, 2013. 
THOMPSON, D. O tubarão de 12 milhões de dólares: a curiosa economia da arte contemporânea. BEI Comunicação, 2012.

VELTHUIS, O. Talking Prices: symbolic meanings of prices on the market for contemporary art. UK: Princeton University Press, 2005.

O. ArtRank ant the Flippers: Apocalypse Now? In: Texte Zur Kunst. 24 de dezembro de 2014. Jahrgang, Heft 96, p. 34-49.

ZIZEK, S. Primeiro como tragédia, depois como farsa. São Paulo: Boitempo, 2011.

Recebido em: 15/06/2017 - Aprovado em 21/08/2017 